\title{
Perfomansi Pemanas Air Tenaga Surya Dengan Penambahan Sirip Pada Kolektor
}

\author{
H. Ambarita, Firman Siahaan, Herdy, H V. Sihombing \\ Departemen Teknik MesinFakultas Teknik Universitas Sumatera Utara \\ Email : himsar@gmail.com
}

\begin{abstract}
The solar energy that reaches the earth's surface can be converted into heat energy using solar collectors. Inside the collector, there are several components including a heating pipe as a medium to drain water to the storage tank. There are several factors that increase the performance of solar collectors including the addition of fins to the pipe which will increase the collector's cross-sectional area. This study compares solar collectors with and without the addition of fins, the aim of improving the performance of solar water heater collectors with the addition of fins. Where the dimensions of the fins used are $50 \times 12 \times 0.3 \mathrm{~mm}$. testing is done by comparing the two collectors. The results showed an increase in temperature in solar water heaters with the addition of fins to the pipe and an increase in efficiency of $18.67 \%$ compared to solar water heaters without the addition of fins.
\end{abstract}

Keywords: water heater, Performance, solar collector, fin

\section{PENDAHULUAN}

Peningkatan pertumbuhan manusia mengakibatkan tingginya kebutuhan akan energi, dimana hal ini mengakibatkan eksplorasi energi secara besar-besaran dilakukan terutama energi fosil. Disamping energi fosil yang terus berkurang, pengunaan energi fosil secara terus-menerus mengakibatakan kondisi lingkungan yang semakin buruk. Ada beberapa strategi untuk menanggulangi emisi gas rumah kaca (GHG) seperti penghijauan dan pengembangan energi terbarukan [1]. Energi surya merupakan salah satu energi terbarukan yang dapat dimanfaatkan sebagai sumber energi alternatif. Indonesia merupakan negara tropis yang mempunyai potensi energi surya yang tinggi. Besarnya potensi radiasi yang dapat di manfaatkan sebesar $4,5 \mathrm{kWh} / \mathrm{m}^{2} / \mathrm{hari}[2,3]$.

Pemanfaatan energi surya yang paling banyak yaitu untuk pemanas. Misalkan untuk pengeringan, untuk memanaskan air, untuk pertumbuhan tanaman dan lain sebagainya. Salah satu pengaplikasian penghasil termal yang banyak digunakan yaitu penggunaan kolektor surya sebagai penghasil air panas. Jenis alat pemanas air tenaga surya yang banyak digunakan yaitu kolektor plat datar, dimana kolektor ini sangat disukai dikarenakan pengoperasiannya yang mudah dan biaya yang dibutuhkan murah. Untuk mendapatkan pemanas air tenaga surya yang optimum banyak penelitian yang telah dilakukan untuk mendapatkan efesiensi optimum dari pemanas air tenaga surya. Adapaun penelitian yang terus dikembangkan seperti pada bagian plat absorber 
kolektor, material insulasi kolektor, pipa aliran fluida, bagian penutup kolektor, penambahan reflector, maupun mengkaji tempat penyimpanan air panas[4-7]. Helmi dan Dwi [8] melakukan pengujian pada kolektor surya sebagai penghasil air panas. Dalam penelitian ini peneliti melakukan pengujian dengan memvariasikan jarak antar pipa pada kolektor. Variasi jarak pipa tembaga yaitu $5 \mathrm{~cm}, 7 \mathrm{~cm}$, dan $9 \mathrm{~cm}$. Dari hasil pengujian jarak pipa $5 \mathrm{~cm}$ memiliki efesiensi tertinggi sebesar 33,33\%. Sourav dkk [9] melakukan pengujian dengan menambahakan sirip pada fotovoltaik, dengan tujuan untuk menjaga temperature fotovoltaik. Dari hasil pengujian adanya peningkatan efesiensi pada fotovoltaik. Ali dan Yahya [10] melakukan pengujian secara eksperimental pada kolektor surya sebagai pompa kalor. Dimana dengan penambahan sirip dapat meningkatkan efesiensi dari $30 \%$ menjadi $50 \%$. Dendi dan Bambang [11] melakukan pengujian pada kolektor surya sebagai pemanas air. Pada penelitian ini dilakukan penambahan eksternal helical fins pada pipa dan dilakukan variasi sudut kemiringan pada kolektor. Adapun sudut kemiringan kolektor yang digunakan memiliki variasi sudut yang berbeda-beda antara lain $10^{\circ}, 20^{\circ}$ dan $30^{\circ}$. Dari hasil pengujian didapatkan bahwa efesiensi kolektor surya sebagai pemanas air dengan penambahan eksternal helical fin pada pipa dengan sudut kemiringan kolektor $30{ }^{0}$ memiliki efesiensi tertinggi dibandingkan sudut lainnya sebesar $65,81 \%$. Banyaknya penelitian tentang kolektor membuat peneliti mencoba membangun kolektor surya sebagai pemanas air dan menembahkan sirip pada kolektor. Dengan maksud untuk mengetahui seberapa besar peningkatan effesiensi kolektor surya penambahan sirip.

Adapun tujuan dari penelitian ini adalah membangun serta menguji kolektor surya sebagai pemanas air, dimana pada penelitian ini akan di uji pemanas air tenaga surya dan membandingkannya dengan pemanas air tenaga surya dengan penambahan sirip pada bagian pipa kolektor surya. Dengan penambahan sirip akan menambah luas penampang kolektor sehingga mampu menyerap panas lebih banyak. Pompa DC akan digunakan sebagai sumber tenaga untuk mengalirkan fluida dari dalam pipa kolektor ke bak pempungan. Dalam hal ini pyranometer akan digunakan untuk mengukur besarnya intensitas matahari selama pengujian.

\section{METODOLOGI PENELITIAN}

\subsection{Bahanpengujian}

Kolektor surya yang digunakan double penutup kolektor dengandimensi 1,6 x 1,1 m dan ketebalannya $0,08 \mathrm{~m}$, dengan ketebalan tiap penutup kolektor $5 \mathrm{~mm}$, pipa tembaga yang digunakan berdiameter 0,5 in, material sirip pada pipa yang digunakanya itu pelat tembaga dengan ketebalan $0,5 \mathrm{~mm}$, absorber terbuat dari pelat aluminium ketebalan 0,6 $\mathrm{mm}$. Fotovoltaik dengan kapasitas $100 \mathrm{WP}$ digunakan sebagai sumber tenaga pada pompa DC. 


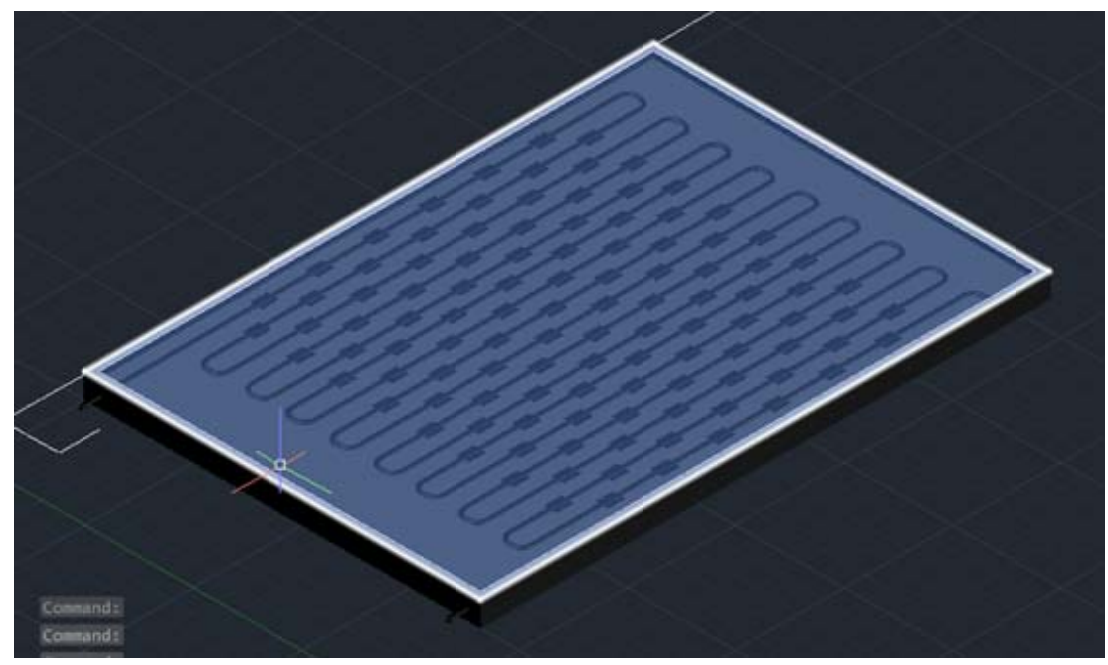

Gambar 1. Kolektor surya dengan penambahan sirip

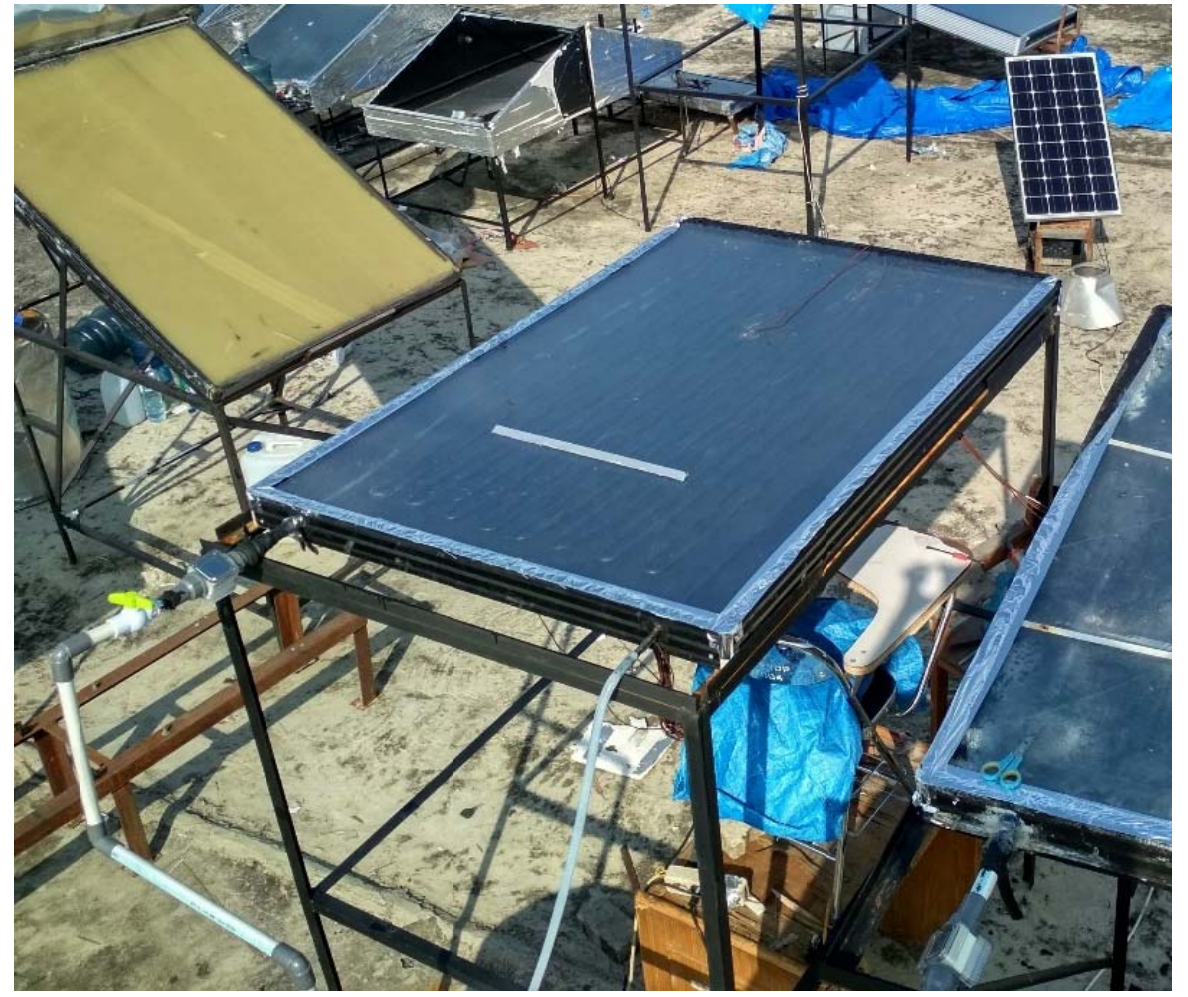

Gambar 2. Instalasi pengujian kolektor surya dengan penambahan sirip

\subsection{Prinsip Pengujian}

Penelitian ini dilakukan di laboratorium Sustainable Energy Research Center Universitas Sumatera Utara pada bulan Mei-Agustus 2019. Pengujian dilakukan dengan memvariasikan pipa kolektor surya, dimana pada salah satu kolektor dilakukan penambahan sirip.Adapun komponen utama dalam penelitian ini antara lain bak penampungan air, kolektor surya sebagai tempat air bersirkulasi air, fotofoltaik digunakan sebagai sumber tenaga untuk mengalirkan fluida dari dalam pipa kolektor menuju bak penampungan air panas. Pengambilan data dilakukan mulai pukul 08.00- 
16.00 WIB dengan rentang waktu satu jam. Parameter yang diukur dalam penelitian ini antara lain temperature udara lingkungan $\left(\mathrm{T}_{\infty}\right)$, kecepatan angin $(\mathrm{v})$, temperature kaca sisi atas $\left(T_{1}\right)$, temperature kaca sisi bawah $\left(T_{2}\right)$, temperatur pipa $\left(T_{p}\right)$, temperature absorber $\left(\mathrm{T}_{\mathrm{abs}}\right)$, temperatur air masuk $\left(\mathrm{T}_{\mathrm{i}}\right)$ dan temperatur air keluar $\left(\mathrm{T}_{\mathrm{o}}\right)$. Pada pengujian ini radiasi di ukur dengan rentang waktu 5 menit menggunakan HOBO-Micro station. Skema pengujian dari penelitian yang dilakukan dapat dilihat pada gambar 2, dimana air dipompakan ke dalam kolektor surya untuk dipanaskan oleh energi surya. Air akan dipompakan dari dalam bak penampung masuk ke dalam pipa pada kolektor dan kembali masuk ke dalam bak penampung dan kembali bersirkulasi secara terus menerus sampai suhu air meningkat. Pada penelitian ini pompa akan mengalirkan air dari dalam bak penampung ketika masih ada radiasi dari matahari. Ketika radiasi tidak ada maka pompa akan secara otomatis tidak mengalirkan air kedalam kolektor surya.

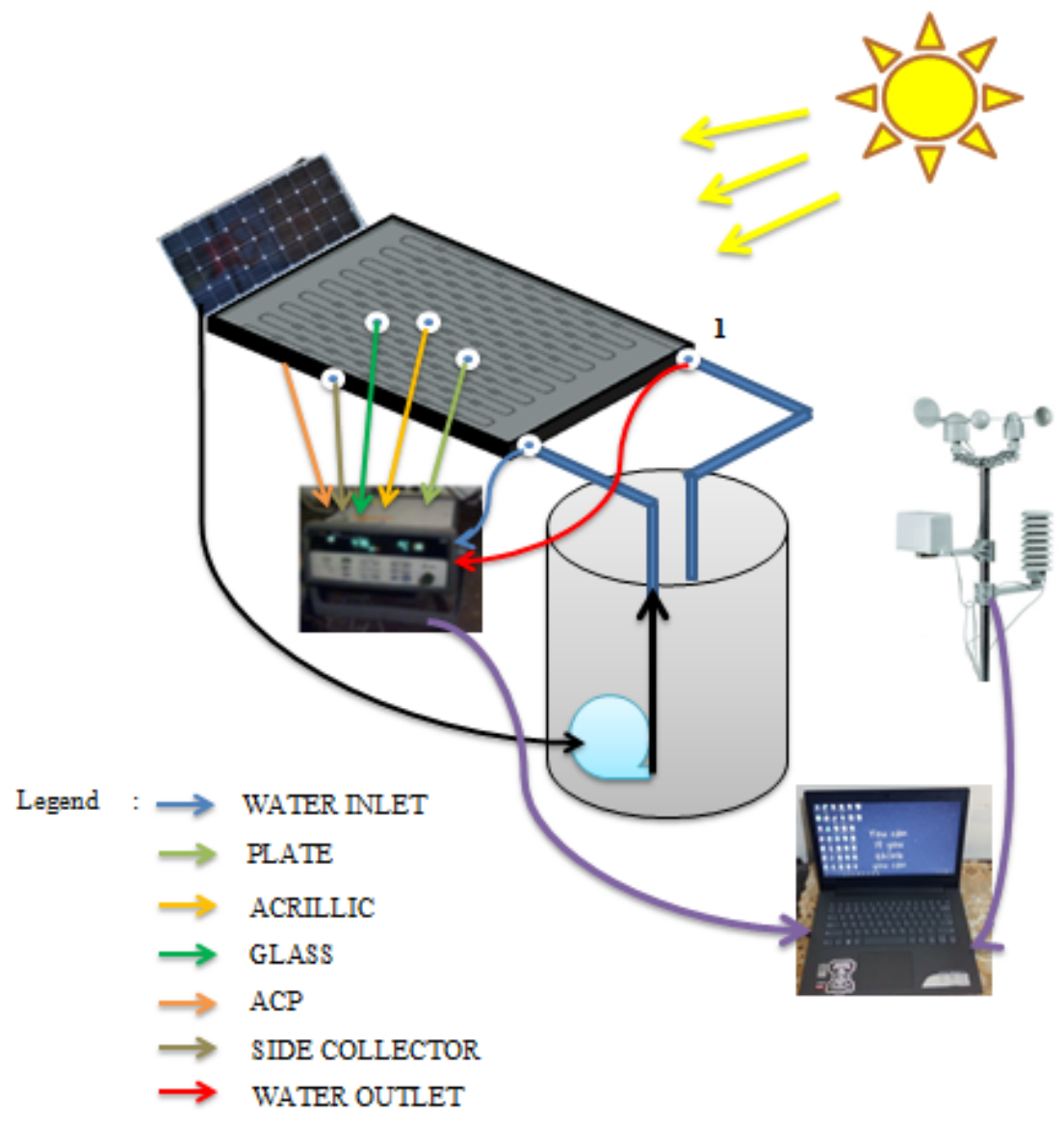

Gambar 3. Skema Pengujian Pemanas Air Tenaga Surya

\subsection{Parameter Kolektor Surya}

Parameter dari kolektor surya secara khusus ditunjukkan seperti berikut [11]. Energi yang diterima kolektor dihitung berdasarkan data actual yang diperoleh dari alat ukur HOBO-Ware station. Untuk memperoleh total panas yang diterima pada kolektor menggunakan persamaan berikut ini

$$
Q_{\text {in }}=A \int_{1}^{2} q_{\text {radiasi }} d t
$$


Besarnya panas yang dibutuhkan untuk memanaskan air kapasitas 120 liter hingga mencapai $50{ }^{\circ} \mathrm{C}$ menggunakan persamaan berikut ini

$$
Q_{\text {kolektor }}=m C p(\Delta T)
$$

Dimana $m$ merupakan massa air $(\mathrm{kg})$, Cp merupakan panas jenis dari air $\left(\mathrm{kJ} / \mathrm{kg} .{ }^{0} \mathrm{C}\right)$ sementara $\mathrm{T}_{1}$ dan $\mathrm{T}_{2}$ merupakan suhu awal dan akhirdari air dalam kolektor $\left({ }^{0} \mathrm{C}\right)$.

Effesiensi termal kolektor merupakan perbandingan nilai antara energi yang digunakan untuk memanaskan air air $\left(\mathrm{q}_{\mathrm{use}}\right)$ dengan energi yang diterima oleh kolektor $\left(\mathrm{q}_{\text {in }}\right)$.

$$
\eta=\frac{q_{\text {use }}}{q_{\text {in }}}
$$

Effesiensi sirip dapat dihitung melalui perbandingan antara banyaknya panas yang dilepas dengan banyaknya panas yang dipindahkan juka seluruh sirip suhunya sama dengan suhu dasar sirip, dapat dinyatakan dengan persamaan berikut:

$$
\eta=\frac{h A_{s i}\left(T_{i}-T_{\infty}\right)}{h A_{s f}\left(T_{b}-T_{\infty}\right)}
$$

Dimana $h$ merupakan Koefisien perpindahan panas konveksi $\left(\mathrm{W} / \mathrm{m} 2 .{ }^{\circ} \mathrm{C}\right), \mathrm{A}_{\mathrm{si}}$ merupakan luas permukaan sirip yang bersentuhan dengan fluida $\left(\mathrm{m}^{2}\right), \mathrm{A}_{\mathrm{sf}}$ merupakan luas permukaan seluruh sirip yang bersentuhan dengan fluida $\left(\mathrm{m}^{2}\right), \mathrm{T}_{\mathrm{i}}$ merupakan suhu sirip $\left({ }^{0} \mathrm{C}\right), \mathrm{T}_{\infty}$ merupakan suhu lingkungan $\left({ }^{0} \mathrm{C}\right)$, dan $\mathrm{T}_{\mathrm{b}}$ merupakan suhu dasar sirip $\left({ }^{0} \mathrm{C}\right)$.

\section{HASIL DAN PEMBAHASAN}

\subsection{Pengujian}

Temperatur pada kolektor surya diukur dengan menggunakan Agilent data logger selama 7 hari. Pengukuran temperatur kolektor surya dilakukan setiap interval waktu 1 jam selama 8 jam yang dimulai pukul 08.00 sampai pukul 16.00 WIB. Pengukuran temperature ini dilakukan untuk mengetahui distribusi temperatur pada kolektor surya dan seberapa besar panas yang diserap oleh pipa -pipa maupun sirkulasi air. Pada gambar 5 pengukuran intensitas radiasi dilakukan selama pengujian. Peningkatan maupun penurunan temperatur pelat absorber sangat dipengaruhi jumlah radiasi yang diserap oleh kolektor. Semakin tinggi radiasi matahari maka semakin tinggi temperatur plat absorber maupun air pada kolektor surya.

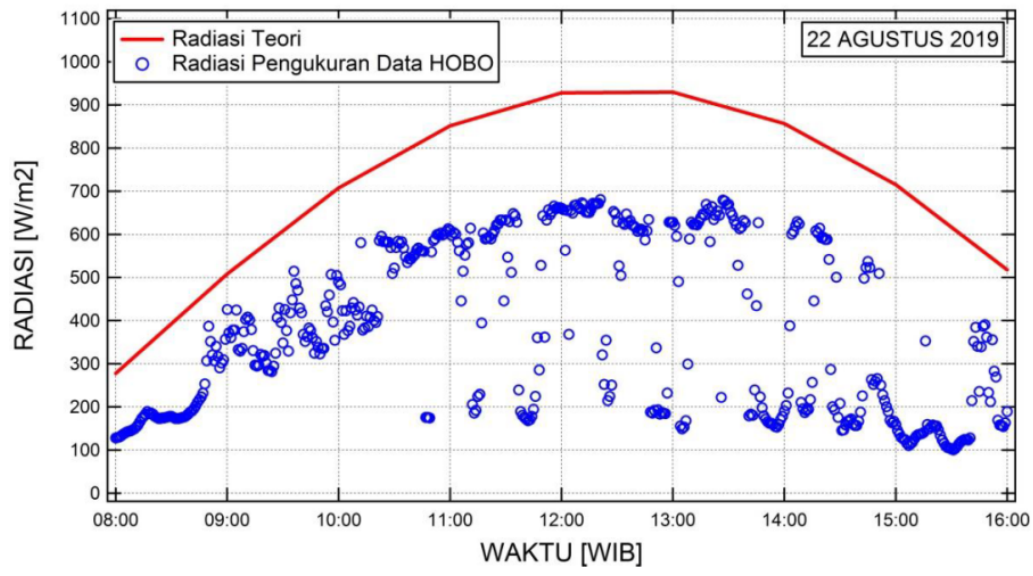

Gambar 4. Pengukuran radiasi 
Pada tabel 1 ditunjukkan temperatur pada kolektor surya pada pukul 13.44 WIB, dimana pada waktu tersebut radiasi tertinggi pada saat pengukuran. Pengukuran dilakukan pada kedua pemanas air tenaga surya. Dari hasil pengukuran pemanas air tenaga surya $(\mathrm{SWH})$ diperoleh bahwa rata-rata temperature pemanas air tenaga surya dengan penambahan eksternal fin (SWH II) memiliki temperature lebih tinggi sebesar 4 $\%$ dibandingkan dengan pemanas air tenagasurya tanpa modifikasi (SWH I). Tinggi rendahnya temperatur air yang dihasilkan pemanas air tenaga surya dipengaruhi oleh intensitas matahari. Semakin tinggi intensitas matahari mengakibatkan temperatur air semakin tinggi.

Tabel 1. Temperatur pada titik yang diukur

\begin{tabular}{llccc}
\hline No & Titik yang diukur & Waktu & $\begin{array}{c}\text { Temperatur pada SWH I } \\
\left({ }^{\mathbf{0}} \mathbf{C}\right)\end{array}$ & $\begin{array}{c}\text { Temperatur pada SWH II } \\
\left({ }^{\mathbf{0}} \mathbf{C}\right)\end{array}$ \\
\hline $\mathbf{1}$ & Plat absorber & & 70,21 & 73,14 \\
$\mathbf{2}$ & Ruangkolektor & & 65,30 & 63,44 \\
$\mathbf{3}$ & Acrylic & 52,23 & 49,93 \\
$\mathbf{4}$ & Kaca & 55,29 & 61,49 \\
$\mathbf{5}$ & Air masukKoil & & 45,65 & 48,67 \\
$\mathbf{6}$ & Air KeluarKoil & & 51,66 & 54,49 \\
$\mathbf{7}$ & Tangki Air & 44,82 & 48,82 \\
\hline
\end{tabular}

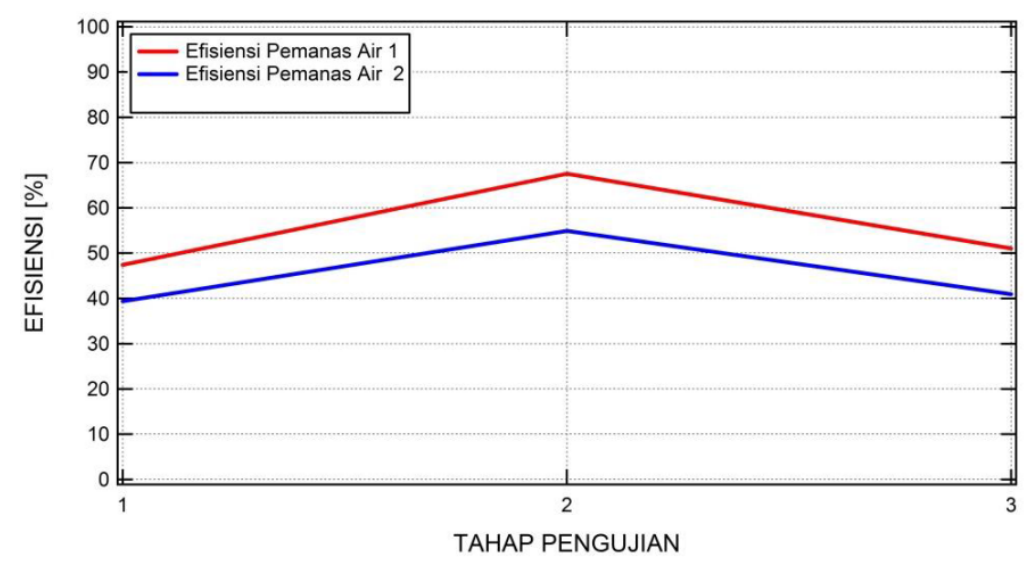

Gambar 5. Perbandingan efesiensi pemanas air tenaga surya

Dari hasil pengujian seperti ditunjukkan pada gambar 5 rata-rata nilai efesiensi pemanas air tenaga surya tanpa penambahan sirip yaitu 54,91 \% sedangkan rata-rata nilai efesiensi pemanas air tenaga surya dengan penambahan sirip yaitu sebesar 67,52\% atau nilai efesiensi pemanas air tenaga surya dengan penambahan sirip memiliki efesiensi lebih tinggi 18,67 \% dibandingkan dengan tanpa penambahan sirip. Perbandingan efisiensi pengujian yang dilakukan dapat dilihat pada tabel 2 dan tabel3. Dari hasil pengujian diperoleh bahwa pemanas air tenaga surya dengan dilakukannya penambahan sirip memiliki tingkat effesiensi lebih tinggi dibandingkan dengan pemanas air tenaga surya tanpa modifikasi. Penyebab pemanas air tenaga surya dengan penambahan sirip memiliki efesiensi lebih tinggi dikarenakan kalor yang diserah oleh kolektor dan air 
lebih tinggi dibandingkan dengan pada pemanas air tenaga surya tanpa menggunakan sirip.

Tabel 2. Pemanas air tenaga surya (tanpa sirip)

\begin{tabular}{lcllll} 
No & Pengujian & $\begin{array}{l}\text { Waktu } \\
\text { Pengujian } \\
\text { (WIB) }\end{array}$ & $\begin{array}{l}\text { T inlet } \\
\left({ }^{\mathbf{0}} \mathbf{C}\right)\end{array}$ & $\begin{array}{l}\text { T oulet } \\
\left(\mathbf{(}^{\mathbf{0}} \mathbf{C}\right)\end{array}$ & $\begin{array}{l}\text { Efisiensi } \\
\mathbf{( \% )}\end{array}$ \\
\hline $\mathbf{1}$ & I & $08.00-16.00$ & 30,09 & 43,09 & 39,36 \\
$\mathbf{2}$ & II & $08.00-16.00$ & 27,59 & 45,53 & 54,91 \\
$\mathbf{3}$ & II & $08.00-16.00$ & 30,57 & 40,92 & 40,92 \\
\hline
\end{tabular}

Tabel 3. Pemanas air tenaga surya (dengan menggunakan sirip)

\begin{tabular}{|c|c|c|c|c|c|}
\hline No & Pengujian & $\begin{array}{l}\text { Waktu } \\
\text { Pengujian } \\
\text { (WIB) }\end{array}$ & $\begin{array}{l}\text { T inlet } \\
\left({ }^{\circ} \mathrm{C}\right)\end{array}$ & $\begin{array}{l}\text { T } \\
\text { oulet } \\
\left({ }^{0} \mathrm{C}\right)\end{array}$ & $\begin{array}{l}\text { Efisiensi } \\
(\%)\end{array}$ \\
\hline 1 & I & $08.00-16.00$ & 31,23 & 46,89 & 47,41 \\
\hline 2 & II & $08.00-16.00$ & 27,78 & 49,84 & 67,52 \\
\hline 3 & II & $08.00-16.00$ & 30,96 & 42,87 & 51,03 \\
\hline
\end{tabular}

\section{KESIMPULAN}

Pemanas air tenaga surya masih sangat memungkinkan untuk terus dikembangkan untuk mendapatkan meningkatkan efesiensi pemanas air tenaga surya. Dari hasil pengujian dimana dilakukan peningkatan efesiensi pemanas air tenagasurya yaitu dengan penambahan sirip pada pipa. Hasil menunjukkan adanya kenaikan temperatur pada pemanas air tenaga surya dengan penambahan sirip serta peningkatan efesiensi sebesar $18,67 \%$ dibandingkan pemanas air tenaga surya tanpa penambahan sirip.

\section{DAFTAR PUSTAKA}

[1] Ambarita H dan Sihombing H.V. 2018.IOP.Conf. Series: Journal of Physics 978, 012098.

[2] Alqadry, Hutagalung T, Kevinta H. J.M, Napitupulu R A.M, Ambarita H. 2020. IOP Conf. Series: Materials Science and Engineering 725012018.

[3] Ambarita H. 2018. IOP Conf. Series: Materials Science and Engineering 420 012013.

[4] Alifdini I, Iskandar N.A.P, Nugraha A.W, Sugianto D.N, Wirasatriya A, Widodo A.B. 2018. Oceam Engineering 165 34-42.

[5] Hashim W M, Shomran A T, Jurmut H A, Gaaz T S, Kadhum A A H, Ahmed A, Almiery A. 2018. Case Studies in Thermal Engineering 12 666-671.

[6] Andoh H.Y, Gbaha P, Koua B.K, Koffi P.M.E, Toure S. 2010. Energy for Sustainable Development 14 297-301. 
[7] Lizama-Tzec F.I, Herrera-Zamora D.M, Ares-Muzio O, Gomez-Espinoza V.H, Santos-Gonzalez I, Cetina-Dorantes M, Vega-Poot A.G, Gracia-Valladares O, Oskam G. 2019. Solar Energy 194 302-310.

[8] Li S, Zhang Y, Zhang K, Li X, Li Y, Zhang X. 2014. Energy Procesia48 384-393.

[9] Khanna S, Reddy K.S, Mallick T. K, 2018. International Journal of Thermal Sciences 130 313-322.

[10] Daliran A, Ajabshirchi Y. 2018. Information Processing in Agriculture 5 411-421.

[11] Nugraha D, Dwiyantoro A.A. 2015. Jurnal Teknik ITS Vol. 4, No. 1, ISSN: 23373539 